\title{
Understanding the Facilitators and Barriers to COVID-19 Vaccine Uptake Among Teachers in the Sagnarigu Municipality of Northern Ghana: A Cross-Sectional Study
}

\author{
Stephen Dajaan Dubik (D) \\ Department of Public Health, Catholic University College of Ghana, Fiapre, Ghana \\ Correspondence: Stephen Dajaan Dubik, Email stephendubik@gmail.com
}

Purpose: This research aims to identify facilitators and barriers to COVID-19 vaccination intention and uptake among teachers in the Sagnarigu Municipality of Ghana.

Methods: The survey collected quantitative data from the teachers using a cross-sectional study design. Logistic regression analysis was used to identify facilitators and barriers to COVID-19 vaccination.

Results: The teachers' $(\mathrm{N}=421$ ) COVID-19 vaccination intention before rollout, after rollout, and actual uptake were $49 \%, 63 \%$, and $11 \%$, respectively. In a multiple regression analysis, key facilitators of intention were vaccinated against hepatitis B (AOR: $2.5,95$ CI: 1.03, 4.93), willingness to recommend COVID-19 vaccine to students (AOR: 4.78,95\% CI: 1.95, 11.70), adequacy of information about the expectation of the COVID-19 vaccine (2.42, 95\% CI: 1.04, 5.56), and the disbelief that COVID-19 vaccine will cause illness (AOR: 2.50, 95\% CI: 1.16, 5.33). Unconfident in the COVID-19 vaccine (AOR: 0.01, 95\% CI: 0.001, 0.118), perception of not being susceptible to COVID-19 (AOR: 0.38, 95\% CI: 0.17, 0.88), and feeling uncomfortable getting the vaccine (AOR: 0.17, 95\% CI: 0.08, 0.38) were barriers to COVID-19 vaccination intention. Key facilitators of COVID-19 vaccine uptake were being a Christian (AOR: 3.63, 95\% CI: 1.60, 8.24), teaching in the Senior High School (SHS)/technical (AOR: 13.43, 95\% CI: 1.90, 9.48). Barriers to the vaccine uptake were uncomfortable getting the vaccine (AOR: 0.06, 95\% CI: 0.06, 0.49), disbelief that vaccinating teachers will reduce school absenteeism (AOR: 0.45, 95\% CI: 0.18, 1.07), unconfident in the COVID-19 vaccine (AOR: 0.45, 95 CI: 0.18, 1.07), and unavailability of the COVID-19 vaccine.

Conclusion: Facilitators and barriers to COVID-19 vaccination are multifaceted, including sociodemographic, health beliefs, and contextual factors. Addressing the obstacles to COVID-19 vaccination is crucial for adequate COVID-19 vaccine coverage among teachers in Ghana.

Keywords: COVID-19 vaccination, barriers, vaccine uptake, school health, teachers, Ghana

\section{Introduction}

The coronavirus disease-2019 (COVID-19) has spread to all continents, causing significant public health crises. ${ }^{1}$ Globally, data reported to the WHO showed COVID-19 has infected over 200 million individuals, yielding over 4 million mortalities as of 17 August 2021. ${ }^{1}$ The Republic of Ghana has reported more than 100 thousand confirmed cases of COVID-19 and 945 deaths as of 14 August 2021. ${ }^{2}$ Public health prevention measures such as washing hands, wearing masks, avoiding crowded places, and physical distancing are recommended for the prevention and control of the COVID-19 pandemic. $^{3}$ In addition to these public health preventive measures, there are safe and efficacious COVID-19 vaccines for immunization against the global pandemic. ${ }^{4}$ Indeed, the role of the COVID-19 vaccine in preventing SARSCOV-2 infection has long been established by scholars. ${ }^{5-8}$ Therefore, the COVID-19 vaccine is recommended for all qualified individuals, including teachers. 6,7 
Despite the potential role of the COVID-19 vaccine in preventing SARS-COV-2 infections, there are reports of vaccine hesitancy. For instance, preliminary studies in Ghana showed that vaccine acceptance ranges from 39-70\% among health workers ${ }^{9,10}$ and 51-54\% among the general population. ${ }^{11,12}$ In the Republic of Nigeria, only $50 \%$ of the sample were willing to accept the COVID-19 vaccine. ${ }^{13}$ Those unwilling to receive the COVID-19 vaccine raise concerns of safety, efficacy, effectiveness, side effects, and rust in developing the COVID-19 vaccine as the primary reasons for their hesitancy. ${ }^{9,12,14}$ In African countries, the COVID-19 vaccination rollout has been constrained by the unavailability of COVID-19 vaccines due to limited funds, storage requirements, and conflicts. ${ }^{15}$ Lastly, a recently published study in Ethiopia showed sociodemographic factors and health beliefs of the individual plays a role in COVID19 vaccine acceptance. ${ }^{16}$

Ghana started its COVID-19 vaccination campaigns on 1 March 2021 after receiving 600,000 initial doses of the AstraZeneca vaccine through the COVAX facility. ${ }^{17}$ These initial doses were meant for healthcare workers and people with underlying medical conditions. As of 27 January 2022, Ghana has administered over 10 million doses of COVID-19 vaccine comprising 6,712,407 AstraZeneca, 17,982 Sputnik V, 1,048,590 Moderna, 1,505,552 Pfizer-BioNTech and 740,950 COVID-19 vaccine Janssen. ${ }^{17}$

Early studies conducted in developed countries showed actual COVID-19 uptake among the general population ranges from $51 \%-89 \%{ }^{18-20}$ This indicates that COVID-19 vaccine uptake is a significant problem that needs serious attention. Several scholars have investigated factors associated with COVID-19 vaccine acceptance and uptake among healthcare workers. ${ }^{9,20,21}$ These studies are necessary since healthcare workers are at heightened risk of acquiring the SARS-COV-2. Like healthcare workers, teachers work in environments suitable for COVID-19 spread, elevating the teacher's risk of contracting the COVID-19 virus and possible spread to their families and students. Indeed, there are concerns about school reopening and COVID-19 transmission in the schools. ${ }^{22,23}$ Additionally, teachers' vaccine acceptance and subsequent uptake are crucial for the continuous functioning of schools, ensuring the teachers' safety and protection of school children. Against this backdrop, the United Nation's Children Emergency Fund (UNICEF) calls for the prioritization of teachers to receive the COVID-19 vaccine following vaccination of healthcare workers and highrisk populations. ${ }^{24}$

Despite this call by the UNICEF, there is limited data regarding Ghanaian teachers' COVID-19 vaccination intention and uptake since the rollout of the COVID-19 vaccination in Ghana. Earlier studies on COVID-19 vaccine acceptance in Ghana have primarily focused on healthcare workers ${ }^{9}$ and the general population. ${ }^{11,12}$ To date, no research has been conducted to evaluate COVID-19 vaccination intention and uptake among teachers in Ghana. Therefore, this present study examines facilitators and barriers to COVID-19 vaccination intention and uptake among teachers in the Sagnarigu Municipality of Ghana. This study is crucial as it will form the scientific basis for interventions to ensure adequate COVID-19 vaccine coverage among teachers in Ghana.

\section{Materials and Methods Study Design and Setting}

The study was a cross-sectional study conducted among teachers in Sagnarigu Municipality of Ghana. This study was conducted following guidelines for reporting cross-sectional surveys. ${ }^{25}$ The study was undertaken between April 2021 to September 2021. Sagnarigu Municipality is one of the municipalities in the Northern region of Ghana. The Municipality, which was carved out of the Tamale metropolis in 2012 by legislative instrument 2066, shares boundaries with Savelugu, Tolon, and Kumbungu Districts. The Sagnarigu municipality has 86 communities and covers a land size of $200.4 \mathrm{~km}^{2}{ }^{26}$ The estimated population of the Sagnarigu municipality is 186,796 , with a male population of 93,761 .

The Sagnarigu Municipality is home to notable Senior High Schools (SHSs) such as Tamale SHS, Tamale Technical Institute, Northern School of Business, Tamale Business Senior High, and Islamic Science Senior High School. The Municipality housed about 205 basic schools comprising 33 nursery/Kindergarten, 119 primary schools, and 53 Junior High Schools (JHSs). The Municipality has over 2000 teachers at the basic school level. ${ }^{26}$ 


\section{Study Population, Sample Size, and Sampling}

The study participants were teachers in the primary, Junior high, and Senior High schools located within the catchment area of the Sagnarigu Municipality. The sample size for the study was determined using the Cochran formula ${ }^{27}$ at $95 \%$ confidence interval, $5 \%$ margin of error, and vaccine acceptance of $54 \%$ from a previous study in Ghana. ${ }^{11}$ The minimum sample size was 420 study subjects after adjusting for a $10 \%$ non-response rate.

The study participants were selected using a cluster and consecutive sampling technique. First, Sagnarigu was divided into three area councils: Sagnarigu-Choggu, Kalpohin, and Kanvilli. Ten schools from each area council were randomly selected through the lottery method. The names of all the schools in each area council were written on papers and placed in a bowl for selection without looking into the bowl. The sample size was proportionally allocated to these area councils based on the number of schools in each area council. The teachers in the schools were selected through consecutive sampling. That is, teachers who met the inclusion criteria and consented to participate were given a questionnaire to complete until the allocated number for the school was reached.

\section{Data Collection Procedure}

The data were collected through self-administration. The questionnaire (supplementary File 1) was distributed to the consented teachers by the research assistants at their schools. This enables the teachers to answer the questions at their convenience. For each distributed questionnaire, one week period was given before collection. The study tool was developed and modified to suit the study after reviewing previous literature. ${ }^{19,28,29}$ The study tool consisted of sociodemographic information, COVID-19 vaccine uptake, intention, and attitudes towards the COVID-19 vaccine. The study tool was pretested on $5 \%$ of the study sample size, and questions that needed modification were modified accordingly.

The study was conducted per the Helsinki declaration for medical research. ${ }^{30}$ Approval for the study was obtained from the Municipal Education Directorate of the Ghana Education Service (GES/NR/SMEO/MC41). Informed consent was obtained from all study participants before distributing the study questionnaire. The study was completely anonymous, and no personal identifiers were collected in the entire data collection process.

\section{Study Variables}

The explanatory variables of the study were age, gender, religion, marital status, educational qualification, number of children, presence of chronic disease, and willingness to recommend the COVID-19 vaccine to students. The explanatory variables also included the teachers' attitudes toward the COVID-19 vaccine (supplementary file 1).

The outcome variables of the study were the intention to receive the COVID-19 vaccine and COVID-19 vaccine uptake.

Intention before rollout: It was measured by asking the teachers, "Before the rollout of the COVID-19 vaccination in Ghana, did you intend to take the vaccine when made available?". There were two responses: "Yes" and "No."

Current intention to receive the COVID-19 vaccine: It was also evaluated by asking the teachers, "Currently, do you intend to receive the COVID-19 Vaccine when it is made available to you?" and the responses were "Yes" and "No." The study used the current intention to identify predictors of COVID-19 vaccination intention since intent before rollout might be prone to recall bias. Additionally, the current intention was also assessed for only the unvaccinated teachers.

COVID-19 vaccine uptake: It was measured by asking whether "they have been vaccinated against COVID-19," and the responses were "Yes" and "No."

\section{Statistical Analysis}

The data were entered into an excel template and transported into STATA 16.0 for analysis. The data were summarized using descriptive statistics such as mean and standard deviation for continuous variables; frequency and percentages for categorical variables. Inferential statistics were performed using the Chi-square test of independence and multivariate logistic regression to identify facilitators and barriers to the teachers' COVID-19 vaccine uptake and intention. A variable was included in the multivariate logistic if that variable were significant during the Chi-square test at a P-value less than 0.05 . 


\section{Results}

\section{Sociodemographic Characteristics of the Study Sample}

School teachers (19-68 yrs, mean age, SD: $35.5 \pm 8.8, \mathrm{n}=421)$ participated in the study. Most (56\%) of the study participants were males, $71 \%$ were married, and $62 \%$ were affiliated with the Islamic religion. A significant majority $(84 \%)$ of the teachers were from the public school, $43 \%$ were teaching at the primary level, and most (61\%) of the study participants had a first degree as their highest qualification. More than half $(67 \%)$ of the study participants reported receiving the hepatitis B vaccine. A vast majority (79\%) of the teachers were willing to recommend the COVID-19 vaccine to their students (Table 1).

\section{COVID-19 Vaccine Intention and Uptake Among School Teachers}

The reported intention to receive the COVID-19 before its rollout in Ghana was 49\%, while the study participants' intention after rollout was $63 \%$. There were significant differences between intention to receive before and after rollout $(\mathrm{P}<0.001)$. Additionally, there was a significant difference between reported intention before rollout and actual uptake of the vaccine $(\mathrm{P}<0.001)$. COVID-19 vaccine uptake rate was $11 \%$, and about $52 \%$ of the vaccinated have completed the COVID-19 vaccination. Preferred vaccines for the unvaccinated intending to receive were John \& Johnson (66\%) and AstraZeneca (20\%). A little over $27 \%$ were completely confident in the effectiveness of the COVID-19 vaccine (Table 1 ).

\section{Motivation for Receiving the COVID-19 Vaccine}

The three top reasons for receiving the COVID-19 vaccine were prevention of COVID-19 (84\%), help protect my families, friends, and the community (75\%), and protection of students/pupils (52\%) (Table 2).

\section{Reasons for Not Receiving the COVID-19 Vaccine}

The three top reasons for not receiving the COVID-19 vaccine were unavailability of the COVID-19 vaccine (52\%), concern about side effects from the vaccine (45\%), and lack of knowledge about the COVID-19 vaccine (20\%) (Table 2).

\section{Facilitators and Barriers to COVID-19 Vaccination Intention}

Facilitators of intent to receive the COVID-19 vaccine were vaccination against Hepatitis B (AOR: 2.5, 95 CI: 1.03, 4.93), willingness to recommend the COVID-19 vaccine to students (AOR: 4.78,95\% CI: 1.95, 11.70), having adequate information about the expectation of the COVID-19 vaccine (AOR: 2.42, 95\% CI: 1.04, 5.56). Intention to receive the COVID-19 vaccine was less likely among teachers who had no confidence in the effectiveness of the COVID-19 vaccine (AOR: 0.01, 95\% CI: 0.001, 0.118) (Table 3).

Intention to receive the COVID-19 vaccine was also less likely among respondents who were uncomfortable in getting the COVID-19 vaccine (AOR: 0.17, 95\% CI: 0.08, 0.38) and those who disagree that they are more likely to contract COVID-19 (AOR: $0.38,95 \%$ CI: 0.17, 0.88). On the contrary, teachers who disagree that the COVID-19 vaccine will make them sick were 2.5 times more likely to intend to receive the COVID-19 vaccine (AOR: 2.50, 95\% CI: 1.16, 5.33) (Table 3).

\section{Facilitators and Barriers to COVID-19 Vaccine Uptake Among School Teachers}

Facilitators of COVID-9 vaccine uptake were affiliation to Christianity (AOR:3 0.63, 95\% CI: 1.60, 8.24), teaching in the SHS/technical (AOR: 13.43, 95\% CI: 1.90, 9.48), hepatitis B vaccination (AOR: 3.05, 95\% CI: 0.98, 9.51) and having adequate information about the expectation of the COVID-19 vaccine (AOR: 4.84, 95\% CI: 2.10, 11.65). COVID-19 vaccination was less likely among teachers who were uncomfortable going for the COVID-19 vaccine (AOR: 0.06, 95\% CI: $0.06,0.49$ ) and teachers who disagree that vaccinating teachers will reduce school absenteeism (AOR: $0.45,95 \%$ CI: $0.18,1.07)$. Teachers who were somewhat confident in the effectiveness of the COVID-19 vaccine were less likely to receive the COVID-19 vaccine (AOR: 0.45, 95 CI: 0.18, 1.07) (Table 4). 
Table I Sociodemographic Characteristics and COVID-19 Vaccination of the Study Sample

\begin{tabular}{|c|c|c|}
\hline Variables & $\begin{array}{l}\text { Mean } \\
\text { (SD) }\end{array}$ & Min-Max \\
\hline Age (years) & $35.5(8.8)$ & $19-68$ \\
\hline Working experience & $9.3(7.6)$ & $0-37$ \\
\hline \multirow[t]{2}{*}{ Number of children } & $2.1(1.8)$ & $0-8$ \\
\hline & Frequency & $\begin{array}{l}\text { Percent } \\
\text { (\%) }\end{array}$ \\
\hline \multicolumn{3}{|l|}{ Gender } \\
\hline Female & 186 & 44.2 \\
\hline Male & 235 & 55.8 \\
\hline \multicolumn{3}{|l|}{ Marital status } \\
\hline Married & 298 & 70.8 \\
\hline Separated/Divorced & 8 & 1.9 \\
\hline Single & 115 & 27.3 \\
\hline \multicolumn{3}{|l|}{ Religious affiliation } \\
\hline African Traditional Religion & 4 & I \\
\hline Christianity & 158 & 37.5 \\
\hline Islam & 259 & 61.5 \\
\hline \multicolumn{3}{|l|}{ School type } \\
\hline Day-care/KG & 39 & 9.3 \\
\hline JHS & 174 & 41.3 \\
\hline Primary & 180 & 42.8 \\
\hline SHS/technical & 28 & 6.7 \\
\hline \multicolumn{3}{|l|}{ Ownership of school } \\
\hline Private School & 67 & 16.1 \\
\hline Public school & 350 & 83.9 \\
\hline \multicolumn{3}{|l|}{ Highest qualification } \\
\hline Certificate & I & 0.2 \\
\hline Diploma & 106 & 25.3 \\
\hline First degree & 254 & 60.6 \\
\hline Postgraduate & 31 & 7.4 \\
\hline WASSCE/SSCE & 27 & 6.4 \\
\hline \multicolumn{3}{|l|}{ Age } \\
\hline$\geq 39$ & 265 & 62.9 \\
\hline$\geq 39$ & 156 & 37.1 \\
\hline \multicolumn{3}{|l|}{ Number of children } \\
\hline Less than three & 252 & 60.0 \\
\hline Greater than three & 168 & 40.0 \\
\hline \multicolumn{3}{|l|}{ Teaching experience } \\
\hline$<\mathrm{II}$ & 256 & 60.8 \\
\hline$\geq 11$ & 165 & 39.2 \\
\hline \multicolumn{3}{|c|}{ Received Hepatitis B vaccine } \\
\hline No & 138 & 32.8 \\
\hline Yes & 283 & 67.2 \\
\hline \multicolumn{3}{|c|}{ Willing to recommend COVID-19 vaccine to students } \\
\hline No & 90 & 21.4 \\
\hline Yes & 330 & 78.6 \\
\hline \multicolumn{3}{|l|}{ Presence chronic disease } \\
\hline No & 392 & 93.1 \\
\hline Yes & 29 & 6.9 \\
\hline \multicolumn{3}{|c|}{ Have Family Member diagnosed with COVID-19 } \\
\hline No & 397 & 94.3 \\
\hline Yes & 24 & 5.7 \\
\hline
\end{tabular}

(Continued) 
Table I (Continued).

\begin{tabular}{|c|c|c|}
\hline Variables & $\begin{array}{l}\text { Mean } \\
\text { (SD) }\end{array}$ & Min-Max \\
\hline \multicolumn{3}{|c|}{ Intention before the rollout of COVID-19 vaccination in Ghana } \\
\hline No & 213 & 50.6 \\
\hline Yes & 208 & 49.4 \\
\hline \multicolumn{3}{|l|}{ Received COVID-19 vaccine } \\
\hline No & 377 & 89.5 \\
\hline Yes & 44 & 10.5 \\
\hline \multicolumn{3}{|l|}{ Number of Doses received } \\
\hline I received Single John and Johnson & 3 & 6.8 \\
\hline One dose & 21 & 47.7 \\
\hline Two doses & 20 & 45.5 \\
\hline \multicolumn{3}{|c|}{ Current intention to receive COVID-19 vaccine } \\
\hline No & 141 & 37.4 \\
\hline Yes & 236 & 62.6 \\
\hline \multicolumn{3}{|c|}{ Preferred vaccine for unvaccinated with the intention to receive } \\
\hline AstraZeneca & 46 & 19.5 \\
\hline Johnson and Johnson & 155 & 65.7 \\
\hline Moderna & 5 & 2.1 \\
\hline Pfizer/Biontech & 9 & 3.8 \\
\hline Sinopharm & 3 & 1.3 \\
\hline Sinova-coronavac & I & 0.4 \\
\hline Sputnik v & 17 & 7.2 \\
\hline \multicolumn{3}{|c|}{ Have adequate information about the expectations of the COVID- 19 vaccine } \\
\hline No & 289 & 68.6 \\
\hline Yes & 132 & 31.4 \\
\hline \multicolumn{3}{|c|}{ Have adequate information to make an informed decision to receive the } \\
\hline \multicolumn{3}{|c|}{ COVID-19 } \\
\hline No & 261 & 62.0 \\
\hline Yes & 160 & 38.0 \\
\hline \multicolumn{3}{|c|}{ Confidence in the effectiveness of the COVID-19 vaccine } \\
\hline Completely confident & 113 & 26.8 \\
\hline Not confident at all & 132 & 31.4 \\
\hline Somewhat confident & 176 & 41.8 \\
\hline
\end{tabular}

\section{Discussion}

Teachers are crucial for the continuity of education amid the COVID-19 outbreak and response. The study investigated facilitators and barriers to COVID-19 vaccination intention and uptake among school teachers in the Sagnarigu Municipality of Northern Ghana. The current study is vital as it has provided initial data about COVID-19 vaccination intention, uptake, and associated factors among teachers in Ghana. Sixty-three percent of the unvaccinated teachers intend to receive the COVID-19 vaccine. This finding is higher than earlier studies conducted among the Ghanaian population $^{11,12}$ and Ghana's healthcare workers. ${ }^{9}$ However, the intent in this study is lower than studies conducted elsewhere. ${ }^{31,32}$ The reason for these differences is unclear, but intention to receive the COVID-19 vaccine is affected by a complex web of factors. ${ }^{31-33}$

In this study, teachers intending to go for the COVID-19 vaccine were constraint by the unavailability of the COVID19 vaccine and fear of possible side effects from the vaccine. The challenge of COVID-19 vaccine access in African countries has been emphasized by Nachega et al. ${ }^{34}$ Indeed, Africa's COVID-19 vaccine rollout has been challenged by a low supply of the vaccine. ${ }^{35}$ Other scholars in Ghana have also emphasized the concern of possible side effects from the COVID-19 vaccine. ${ }^{9,12}$ However, side effects and deaths related to the COVID-19 vaccine are uncommon. ${ }^{36}$ 
Table 2 Motivation for and Not Receiving the COVID-19 Vaccine

\begin{tabular}{|l|r|}
\hline Motivation for receiving the COVID-I9 vaccine (N = 44) & $\mathbf{n}(\%)$ \\
\hline Prevention of COVID-I9 & $37(84.1)$ \\
Help protect my families, friends, and the community & $33(75.0)$ \\
Protection of my students/pupils & $23(52.0)$ \\
Protecting myself to avoid school absenteeism & $15(34.0)$ \\
COVID-I9 Vaccine will stop the outbreak & $13(30.0)$ \\
COVID-I9 vaccine is safe & $11(25.0)$ \\
I heard it is recommended to get COVID-I9 Vaccine & $17(16.0)$ \\
Reasons for not receiving the COVID-I9 vaccine (N = 377) & \\
Fear of needles & $34(9.0)$ \\
Lack of knowledge about the COVID-I9 vaccine & $75(20.0)$ \\
I do not need it since I am not in the risk group & $24(6.0)$ \\
The vaccine is not safe & $39(10.0)$ \\
I am against vaccines in general & $17(5.0)$ \\
COVID-I9 vaccine is ineffective & $19(5.0)$ \\
Lack of time & $18(5.0)$ \\
Concerned about side effects & $170(45.0)$ \\
Unavailability of COVID-I9 vaccine & $195(52.0)$ \\
\hline
\end{tabular}

Note: Multiple responses possible.

Ensuring access to the COVID-19 vaccine is vital for guaranteeing adequate COVID-19 vaccine coverage among teachers in the Sagnarigu Municipality of Ghana. Additionally, debunking the misleading claims about post-COVID -19 vaccination deaths and side effects is crucial in facilitating vaccine uptake. Further, to ensure unimpeded access to the COVID-19 vaccine, COVID-19 vaccination centers should be immediately instituted in all schools.

We noticed a remarkable gap between intention to receive the vaccine before rollout and actual vaccine uptake. This is a validation of a recent study that found a significant gap between intention and actual uptake of the COVID-19 vaccine among Poland teachers. ${ }^{37}$ Perhaps, focusing on facilitators and barriers to COVID-19 vaccine uptake may help the teachers translate their intent to actual uptake of the COVID-19 vaccine.

COVID-19 vaccine uptake in the study sample was unacceptably low. This is in variance with a study conducted among teachers in Poland, where over $63 \%$ of the sampled teachers had received the COVID-19 vaccine. ${ }^{37}$ In the United States of America, poorer counties' vaccine uptake rate is $48 \%,{ }^{38}$ higher than COVID-19 vaccine uptake in this present study. Furthermore, a recently published study in Ethiopia showed that vaccine uptake was higher $(62 \%)^{39}$ than teachers in the sagnarigu Municipality. These discrepancies may be due to sociodemographic, beliefs and context-specific factors.

The key motivation for receiving the COVID-19 vaccine was the desire to avoid contracting the COVID-19 virus and for the protection of families, friends, and the community. This aligns with published studies in Poland ${ }^{37}$ and the United States of America. ${ }^{29}$ Public health communication strategies aimed at encouraging COVID-19 vaccine uptake should include these motivators.

We explored facilitators and barriers to COVID-19 vaccination intention and uptake among the school teachers. Compared to Muslim teachers, those aligned to the Christian faith were more likely to receive the COVID-19 vaccine. This finding is a validation of a study conducted in the Eastern African country of Ethiopia. ${ }^{16}$ Religious values might have played a crucial role in COVID-19 vaccine uptake. Public health campaigns aimed at increasing vaccine uptake in this dominant Muslim population should engage religious leaders. Compared to teachers in Daycare/Kindergartens, those in the SHS/Technical schools had higher odds of receiving the COVID-19 vaccine. There have been reported cases of COVID-19 infections in Ghanaian SHSs. ${ }^{40}$ This may be the possible explanation for this finding, as the SHS teachers may consider themselves at risk of contracting the COVID-19 virus.

The study's findings also showed that teachers who previously received the Hepatitis B vaccine were more likely to have COVID-19 vaccination intention; vaccine uptake was also higher among teachers who were previously vaccinated against hepatitis B. In a scoping review, Joshi et al intimated that previous influenza vaccination affected COVID-19 
Table 3 Facilitators and Barriers to COVID-19 Vaccination Intention Among School Teachers in Sagnarigu Municipality

\begin{tabular}{|c|c|c|}
\hline Predictors & AOR $(95 \% \mathrm{Cl})$ & P-value \\
\hline \multicolumn{3}{|c|}{ Received Hepatitis B Vaccine } \\
\hline No & Ref & \\
\hline Yes & $2.56(1.03,4.93)$ & 0.041 \\
\hline \multicolumn{3}{|c|}{ Willing to recommend COVID-19 vaccine to students } \\
\hline No & Ref & \\
\hline Yes & $4.78(1.95,11.70)$ & 0.001 \\
\hline \multicolumn{3}{|c|}{ Have adequate information about the expectations of the } \\
\hline \multicolumn{3}{|l|}{ COVID-19 vaccine } \\
\hline No & Ref & \\
\hline Yes & $2.42(1.04,5.56)$ & 0.040 \\
\hline \multicolumn{3}{|c|}{ Confident in the effectiveness of the COVID- 19 vaccine } \\
\hline Completely confident & Ref & \\
\hline Not confident at all & $0.01(0.001,0.118)$ & $<0.001$ \\
\hline Somewhat confident & $0.13(0.02,1.07)$ & 0.057 \\
\hline \multicolumn{3}{|c|}{ COVID-19 vaccine will make me sick } \\
\hline Agree & Ref & \\
\hline Disagree & $2.50(1.16,5.33)$ & 0.02 \\
\hline \multicolumn{3}{|c|}{ I feel comfortable getting the COVID-19 vaccine } \\
\hline Agree & Ref & \\
\hline Disagree & $0.17(0.08,0.38)$ & $<0.001$ \\
\hline \multicolumn{3}{|c|}{ Compared to my friends, I am more likely to get COVID-I9 } \\
\hline Agree & Ref & \\
\hline Disagree & $0.38(0.17,0.88)$ & 0.024 \\
\hline \multicolumn{3}{|c|}{ My co-worker's think I should get a COVID-I9 vaccine } \\
\hline Agree & Ref & \\
\hline Disagree & $0.24(0.11,0.52)$ & $<0.001$ \\
\hline
\end{tabular}

Abbreviations: AOR, Adjusted odds ratio; $\mathrm{Cl}$, Confidence interval.

acceptance across the globe. ${ }^{41}$ Perhaps, the motivation for Hepatitis vaccination might have played a role in facilitating the teacher's intent to receive the COVID-19 vaccine. A vast majority of the teachers were willing to recommend the COVID-19 vaccine to their students if they were eligible to receive it. This is an encouraging finding and may promote the COVID-19 vaccine uptake among students in Ghana. Indeed, teachers who were willing to recommend the COVID19 vaccine to their students had higher odds of intent to receive the COVID-19 vaccine. The role of teachers in the success of school-based health interventions has been documented in a previous study in Canada. ${ }^{42}$ Engaging the teachers is critical to the successful rollout of COVID-19 vaccination in schools.

Teachers who reported having adequate information about the expectations of the COVID-19 vaccine had higher COVID-19 vaccination intention and uptake. This finding is supported by an earlier study conducted among nursing staff in the United States of America. ${ }^{19}$ Educating the teachers about how the COVID-19 vaccine works may motivate subsequent COVID-19 vaccine uptake. The study found lower odds of intention to receive the COVID-19 vaccine among teachers who had no confidence in the effectiveness of the COVID-19 vaccine. Previous studies among Finnish healthcare workers and American nursing staff support this finding. ${ }^{19,43}$ Furthermore, teachers who were doubtful about the efficacy of the COVID-19 vaccine were less likely to receive the vaccine. Programs that seek to build the teachers' confidence are crucial for increasing vaccine uptake. Such programs should include evidence of the effectiveness of the COVID-19 vaccine in preventing SARS-COV-2 infection.

The teachers' attitudes significantly predicted their intention to receive the COVID-19 vaccine and subsequent vaccine uptake. For instance, teachers who were uncomfortable getting the COVID-19 vaccine had lower COVID-19 
Table 4 Facilitators and Barriers to COVID-19 Vaccine Uptake Among School Teachers in Sagnarigu Municipality

\begin{tabular}{|c|c|c|}
\hline Predictors & $\operatorname{AOR}(95 \% \mathrm{Cl})$ & P-value \\
\hline \multicolumn{3}{|l|}{ Religious affiliation } \\
\hline Islam & Ref & \\
\hline Christianity & $3.63(1.60,8.24)$ & 0.002 \\
\hline \multicolumn{3}{|l|}{ Category of school } \\
\hline Daycare/Kindergarten & Ref & \\
\hline Primary & $0.92(0.21,4.03)$ & 0.915 \\
\hline JHS & $0.88(0.2 I, 3.7 \mathrm{I})$ & 0.851 \\
\hline SHS/Technical & $13.43(1.90,9.48)$ & 0.009 \\
\hline \multicolumn{3}{|c|}{ Received Hepatitis B vaccine } \\
\hline No & Ref & \\
\hline Yes & $3.05(0.98,9.51)$ & 0.049 \\
\hline \multicolumn{3}{|c|}{ Have adequate information about the expectations of the } \\
\hline \multicolumn{3}{|l|}{ COVID-19 vaccine } \\
\hline No & Ref & \\
\hline Yes & $4.84(2.10,11.65)$ & $<0.001$ \\
\hline \multicolumn{3}{|c|}{ Confident in the effectiveness of the COVID-19 vaccine } \\
\hline Completely confident & Ref & \\
\hline Not confident at all & $0.12(0.01,1.05)$ & 0.056 \\
\hline Somewhat confident & $0.26(0.09,0.53)$ & $<0.001$ \\
\hline \multicolumn{3}{|c|}{ I feel comfortable getting the COVID-19 vaccine } \\
\hline Agree & Ref & \\
\hline Disagree & $0.06(0.06,0.49)$ & 0.009 \\
\hline \multicolumn{3}{|c|}{ Vaccinating teachers may reduce work absenteeism } \\
\hline Agree & Ref & \\
\hline Disagree & $0.45(0.18,1.07)$ & 0.048 \\
\hline
\end{tabular}

Abbreviations: AOR, Adjusted odds ratio; Cl, Confidence interval; JHS, Junior High School; SHS, Senior High School.

vaccination intention and uptake. This is in line with a previous study conducted among secondary school teachers in the United States of America. ${ }^{29}$ Additionally, perception of not susceptible to contracting the COVID-19 was a barrier to COVID-19 vaccination intention. In a similar study, Ethiopian teachers' perception of being at risk of contracting the COVID-19 virus was a motivator for COVID-19 vaccination intention. ${ }^{16}$ This finding reinforced that if people perceived themselves at risk of contracting SARS-COV-2, they would be more willing to accept the COVID-19 vaccine. ${ }^{44}$ Disbelief that the COVID-19 vaccine will cause illness was a definite predictor of COVID-19 vaccination intention. This is in line with flu vaccination uptake among Irish Hospital workers. ${ }^{28}$ Addressing the negative attitudes of the teachers may play a crucial role in facilitating vaccine intention and subsequent uptake. Furthermore, the belief that vaccinating teachers will reduce school absenteeism was a key predictor of vaccine uptake. This agrees with a study conducted in Saudi Arabia, where perceived benefit facilitated COVID-19 vaccination intention. ${ }^{32}$

This is the first study to evaluate COVID-19 vaccination intention and uptake among teachers in Ghana. Additionally, the present research is crucial to literature since it evaluated both intent to receive and actual uptake of the COVI-19 vaccine. However, the study design could not allow for causality among variables. The non-probability sampling technique may not allow for the generalizability of the findings.

\section{Conclusion and Recommendations}

This study has contributed to our understanding of teachers' COVID-19 vaccination intention and uptake among teachers in Ghana. The current research has demonstrated a significant increase in the teachers COVID-19 vaccination intention 
before and after rollout in Ghana. The teachers' COVID-19 vaccine uptake was constrained by the unavailability of the COVID-19 vaccine, fear of side effects, and lack of knowledge about the COVID-19 vaccine. Common and divergent facilitators and barriers influenced COVID-19 vaccine uptake among the teachers. These facilitators and barriers are multifaceted, stemming from sociodemographic, health beliefs, and contextual factors. Addressing these facilitators and barriers is crucial for increasing future COVID-19 vaccine uptake among teachers in Ghana. This should include building the confidence of the teachers about the efficacy of the vaccine, dispelling misconceptions about susceptibility and side effects of the COVID-19 vaccine, and ultimately, ensuring that the vaccine is available to those willing to receive it. This is particularly important for adequate COVID-19 vaccine coverage among teachers in Ghana.

\section{Data Sharing Statement}

The data used in this study are available from the author upon reasonable request.

\section{Acknowledgment}

The researcher appreciates the research assistants for the data collection, the teachers for their voluntary participation, and the headteachers for their support in the data collection process.

\section{Author Contributions}

The author made a significant contribution to the work reported, whether that is in the conception, study design, execution, acquisition of data, analysis, and interpretation, or in all these areas; took part in drafting, revising, or critically reviewing the article; gave final approval of the version to be published; have agreed on the journal to which the article has been submitted; and agree to be accountable for all aspects of the work.

\section{Disclosure}

The author declares no competing interests in this work.

\section{References}

1. World Health Organization. WHO Coronavirus (COVID-19) Dashboard. WHO.int; 2021. Available from: https://covid19.who.int/?gclid= Cj0KCQjwvO2IBhCzARIsALw3ASoc_kONsNOjLPur736Yzpzv2DD7-Cj0FI34bEtIEz1jnA0c17AzoocaArgsEALw_wcB. Accessed February 15, 2022.

2. GHS. Situation update, COVID-19 outbreak in Ghana as at 14 August 2021. Ghana Health Service; 2021. Available from: https:/ghs.gov.gh/ covid19/. Accessed February 15, 2022.

3. CDC. How to protect yourself and others. Know how it spreads. CDC. 2021:18-19.

4. WHO. Coronavirus disease (COVID-19): vaccines. World Health Organisation; 2020. Available from: https://www.who.int/news-room/questions-andanswers/item/coronavirus-disease-(covid-19)-vaccines?gclid=Cj0KCQjwvO2IBhCzARIsALw3ASqwMjH4Knv5LS3UY4zz2gCpGO ScCOjdDfAAPhHhLSSgrunHmqvEN7AaAndtEALw_wcB\&topicsurvey=v8kj13. Accessed February 15, 2022.

5. Hitchings MDT, Ranzani OT, Torres MS, et al. Effectiveness of CoronaVac among healthcare workers in the setting of high SARS-CoV-2 Gamma variant transmission in Manaus, Brazil: a test-negative case-control study. Lancet Reg Health Am. 2021:100025. doi:10.1016/j. lana.2021.100025.

6. Thompson MG, Burgess JL, Naleway AL, et al. Interim estimates of vaccine effectiveness of BNT162b2 and mRNA-1273 COVID-19 vaccines in preventing SARS-CoV-2 infection among health care personnel, First responders, and other essential and frontline workers - Eight U.S. Locations, December 2020-March. MMWR Morb Mortal Wkly Rep. 2021;70(13):495-500. doi:10.15585/mmwr.mm7013e3

7. Harder T, Koch J, Vygen-Bonnet S, et al. Efficacy and effectiveness of COVID-19 vaccines against SARS-CoV-2 infection: interim results of a living systematic review, 1 January to 14 May 2021. Eurosurveillance. 2021;26:1-9.

8. Gupta K, O'Brien WJ, Bellino P, et al. Incidence of SARS-CoV-2 infection in health care workers after a single dose of mRNA-1273 vaccine. Annu Rev Plant Biol. 2021;4:17-20.

9. Agyekum MW, Afrifa-Anane GF, Kyei-Arthur F, Addo B. Acceptability of COVID-19 vaccination among health care workers in Ghana. Adv Public Health. 2021;2021. doi:10.1155/2021/9998176

10. Alhassan RK, Owusu-Agyei S, Ansah EK, Gyapong M. COVID-19 vaccine uptake among health care workers in Ghana: a case for targeted vaccine deployment campaigns in the global south. Hum Resour Health. 2021;19(1):1-12. doi:10.1186/s12960-021-00657-1

11. Lamptey E, Serwaa D, Appiah AB. A nationwide survey of the potential acceptance and determinants of covid-19 vaccines in Ghana. Clin Exp Vaccine Res. 2021;10(2):183-190. doi:10.7774/cevr.2021.10.2.183

12. Acheampong T, Akorsikumah EA, Osae-Kwapong J, et al. Examining vaccine hesitancy in Sub-Saharan Africa: a survey of the knowledge and attitudes among adults to receive COVID-19 vaccines in Ghana. Vaccines. 2021;9(8):814. doi:10.3390/vaccines9080814

13. Alice Tobin E, Okonofua M, Adeke A, Obi A. Willingness to accept a COVID-19 vaccine in Nigeria: a population-based cross-sectional study. Cent. African J Public Health. 2021;7(2):53. doi:10.11648/j.cajph.20210702.12 
14. Shekhar R, Sheikh AB, Upadhyay S, et al. COVID-19 vaccine acceptance among health care workers in the United States. Vaccines. 2021;9 (2):1-18. doi:10.3390/vaccines9020119

15. Ayenigbara IO, Adegboro JS, Ayenigbara GO, Adeleke OR, Olofintuyi OO. The challenges to a successful covid-19 vaccination programme in Africa. Germs. 2021;11(3):427-440. doi:10.18683/germs.2021.1280

16. Handebo S, Wolde M, Shitu K, Kassie A. Determinant of intention to receive COVID-19 vaccine among school teachers in Gondar City, Northwest Ethiopia. PLoS One. 2021;16(6):1-11. doi:10.1371/journal.pone.0253499

17. GHS. Situation update, COVID-19 outbreak in Ghana as at 26 January 2022. GHS; 2022. Available from: https:/www.ghs.gov.gh/covid19/. Accessed February 15, 2022.

18. Crawshaw J, Konnyu K, Castillo G, et al. Factors affecting COVID-19 vaccination acceptance and uptake among the general public: a living behavioural science evidence synthesis. 2021:1-54.

19. Baniak LM, Luyster FS, Raible CA, Mccray EE, Strollo PJ. COVID-19 vaccine hesitancy and uptake among nursing staff during an active vaccine rollout. Vaccines. 2021;9:1-12.

20. Pacella-LaBarbara ML, Park YL, Patterson PD, et al. COVID-19 vaccine uptake and intent among emergency healthcare workers: a cross-sectional survey. J. Occup. Environ. Med. 2021;63(10):852-856. doi:10.1097/JOM.0000000000002298

21. Elharake JA, Galal B, Alqahtani SA, et al. COVID-19 vaccine acceptance among health care workers in the Kingdom of Saudi Arabia. Int J Infect Dis. 2021;109:286-293. doi:10.1016/j.ijid.2021.07.004

22. Keeling MJ, Tildesley MJ, Atkins BD, et al. The impact of school reopening on the spread of COVID-19 in England. Philos Trans R Soc B Biol Sci. 2021;376(1829). doi:10.1098/rstb.2020.0261.

23. Tupper P, Colijn C, Maini PK. COVID-19 in schools: mitigating classroom clusters in the context of variable transmission. PLoS Comput Biol. 2021;17(7):1-20. doi:10.1371/journal.pcbi.1009120

24. UNICEF. Teachers should be prioritized for vaccination against COVID-19. UNICEF; 2020. Available from: https://www.unicef.org/lac/en/pressreleases/teachers-should-be-prioritized-vaccination-against-covid-19. Accessed February 15, 2022.

25. Centre C, Vandenbroucke JP. Strengthening the reporting of observational studies in epidemiology (STROBE) statement: guidelines for reporting observational studies. Bull World Health Organ. 2007;335:20-22.

26. Sagnarigu District Assembly. Composite budget for 2018-2021 programme based budget estimates for 2018 sagnarigu district assembly; 2018.

27. Cochran W. Sampling Techniques. John Wiley \& Sons; 1963.

28. Hogan V, Lenehan M, Hogan M, Natin DP. Influenza vaccine uptake and attitudes of healthcare workers in Ireland. Occup Med. $2019 ; 69: 494-499$.

29. Gargano LM, Painter JE, Sales JM, et al. Seasonal and 2009 H1N1 influenza vaccine uptake, predictors of vaccination and self-reported barriers to vaccination among secondary school teachers and staff. Hum Vaccin. 2011;7(1):89-95. doi:10.4161/hv.7.1.13460

30. Kong, H.; West, S. \& States, U. The World Medical Association, Inc. Declaration of Helsinki Ethical Principles for medical research involving human subjects; 2008:1-5

31. Racey CS, Donken R, Porter I, et al. Intentions of public school teachers in British Columbia, Canada to receive a COVID-19 vaccine. Vaccine. 2021;8:100106. doi:10.1016/j.jvacx.2021.100106

32. Alobaidi S. Predictors of intent to receive the COVID-19 vaccination among the population in the kingdom of Saudi Arabia: a survey study. J Multidiscip Healthc. 2021;14:1119-1128. doi:10.2147/JMDH.S306654

33. Ahmed MH, Kanfe SG, Jarso MH. Intention to receive vaccine against COVID-19 and associated factors among health professionals working at public hospitals in resource limited settings. PLoS One. 2021;16(7):1-10. doi:10.1371/journal.pone.0254391

34. Nachega JB, Sam-Agudu NA, Masekela R, et al. Addressing challenges to rolling out COVID-19 vaccines in African countries. Lancet Glob Health. 2021;9(6):e746-e748. doi:10.1016/S2214-109X(21)00097-8

35. Takambou M. Africa: vaccination rollout hindered by hesitancy, low supply. DW; 2021. Available from: https://www.dw.com/en/africa-vaccinationrollout-hindered-by-hesitancy-low-supply/a-58936395. Accessed February 15, 2022.

36. Lamptey E. Post-vaccination COVID-19 deaths: a review of available evidence and recommendations for the global population. Clin Exp Vaccine Res. 2021;10(3):264-275. doi:10.7774/cevr.2021.10.3.264

37. Malesza M, Sobolewska K. COVID-19 vaccine uptake, predictors of vaccination, and self-reported barriers to vaccination among primary school teachers in Poland. 2021:1-23.

38. Beusekom M; Van, Writer, N. \& News, C. Poorer US counties have lower COVID-19 vaccine uptake. 2021:1-2.

39. Terefa DR, Shama AT, Feyisa BR, et al. COVID-19 vaccine uptake and associated factors among health professionals in Ethiopia. Infect Drug Resist. 2021;14:5531-5541. doi:10.2147/IDR.S344647

40. Xinhua. Ghana records 142 COVID-19 cases in schools after reopening; 2021. Available from: http://www.xinhuanet.com/english/2021-02/10/c 139734662.htm. Accessed February 15, 2022.

41. Joshi A, Kaur M, Kaur R, et al. Predictors of COVID-19 vaccine acceptance, intention, and hesitancy: a scoping review. Front Public Health. 2021;9:698111.

42. Gadais T, Caron T, Ayoub MB, Karelis A, Nadeau L. The role of the teacher in the implementation of a school-based intervention on the physical activity practice of children. Int J Environ Res Public Health. 2020;17(19):1-17. doi:10.3390/ijerph17197344

43. Karlsson LC, Lewandowsky S, Antfolk J, et al. The association between vaccination confidence, vaccination behavior, and willingness to recommend vaccines among Finnish healthcare workers. PLoS One. 2019;14(10):e0224330. doi:10.1371/journal.pone.0224330

44. Wong LP, Alias H, Wong P, Lee HY, Abubakar S. The use of the health belief model to assess predictors of intent to receive the COVID-19 vaccine and willingness to pay. Hum Vaccin Immunother. 2020;16(9):2204-2214. doi:10.1080/21645515.2020.1790279 


\section{Publish your work in this journal}

Risk Management and Healthcare Policy is an international, peer-reviewed, open access journal focusing on all aspects of public health, policy, and preventative measures to promote good health and improve morbidity and mortality in the population. The journal welcomes submitted papers covering original research, basic science, clinical \& epidemiological studies, reviews and evaluations, guidelines, expert opinion and commentary, case reports and extended reports. The manuscript management system is completely online and includes a very quick and fair peer-review system, which is all easy to use. Visit http://www.dovepress.com/testimonials.php to read real quotes from published authors.

Submit your manuscript here: https://www.dovepress.com/risk-management-and-healthcare-policy-journal 